\title{
Managing Conflict to be Functional between Principals and Teachers in South African Schools
}

\author{
Gaynor Adams, Bernadictus Plaatjies* \\ School of Education Studies, University of the Free State, Bloemfontein, South Africa
}

Received March 25, 2021; Revised April 28, 2021; Accepted May 28, 2021

\begin{abstract}
Cite This Paper in the following Citation Styles
(a): [1] Gaynor Adams, Bernadictus Plaatjies, "Managing Conflict to be Functional between Principals and Teachers in South African Schools," Universal Journal of Educational Research, Vol. 9, No. 6, pp. 1244-1249, 2021. DOI: 10.13189/ujer.2021.090613.
\end{abstract}

(b): Gaynor Adams, Bernadictus Plaatjies (2021). Managing Conflict to be Functional between Principals and Teachers in South African Schools. Universal Journal of Educational Research, 9(6), 1244-1249. DOI: 10.13189/ujer.2021.090613.

Copyright $\bigcirc 2021$ by authors, all rights reserved. Authors agree that this article remains permanently open access under the terms of the Creative Commons Attribution License 4.0 International License

\begin{abstract}
Principal-teacher conflict has become one of the most serious school-related battles. This type of conflict is detrimental to the school, and this problem is mainly attributed to the conflict that is left unattended or unmanaged. This study, therefore, investigates how the conflict between principals and teachers can be managed. This qualitative study was conducted in the ZF Mgcawu district in the Northern Cape, South Africa. This study followed a case study research design, selecting participants using the purposeful sampling method. Data were collected through the use of open-ended questionnaires and analysed thematically. The study's findings revealed that conflict management should play an important role in managing and reducing principal-teacher conflict. It also confirmed that unattended conflict between principals and teachers have detrimental effects on school culture and that functional conflict management strategies are necessary for conflict to be less destructive in the school environment. It is therefore recommended greater awareness about this topic in general. Specific strategies should be implemented to guide principals as well as teachers on how to manage conflict functionally.
\end{abstract}

Keywords Conflict, Principals/ Teachers, Conflict Management, Functional Conflict Management Strategies/ Approaches

\section{Introduction}

Conflict is an inevitable factor and a social phenomenon that occurs amongst individuals or within groups, organisations, and nations on a daily basis (Mullins, 2010:197). Over the past years, this phenomenon has become a significant concern in organisations, including school settings. Research has shown that sometimes the prevalent conflict between principals and teachers, in particular, has devastating effects on the sustainability of school culture (Squelch \& Lemmer, 1994; Chadwick, 1995; Jones, 2005; Mahomed, 2014; Makibi, 2010; Msila, 2012; Göksoy \& Argon 2016).

Conflict situations can arise from various sources such as diversity, use of power-authority, dress code, leave of absence, poor communication, heavy workloads, reluctancy towards change and a lack of transparency, to mention but a few (Makibi, 2010; Mullins, 2010; Göksoy \& Argon, 2016). Researchers warn against several destructive consequences resulting from the conflict between school principals and teachers in schools. Ohaka (2016), for example, holds that negative conflict situations can have a declining and counterproductive effect on the educational, academic, social and moral development of individuals in the school environment. This, in turn, could lead to job dissatisfaction from teachers, high absenteeism, continuous disturbance of school activities and lack of collaborative work between teachers and principals. Furthermore, Göksoy and Argon (2016:204) believe that conflict in schools could lead to intolerance from staff, violence, the formation of cliques, breakdown in communication and an undisciplined environment.

It is common sense that managing schools and conflict situations, in particular, cannot always be a smooth-sailing 
process. Providing the central focus of any school, though - that is to deliver quality teaching and learning this issue should receive more attention in research. This is especially the case to prevent the quality of teaching and learning at the school from decreasing (Göksoy \& Argon, 2016:200). Msila (2012:25) contends that "there is a huge gap in school management research in that the aspect of conflict management has been neglected". Unmanaged conflict can create dysfunctional schools, depriving learners of their constitutional values such as human dignity and equality. According to Snodgrass and Blunt (in Msila, 2012), these values cannot be attained in an atmosphere and in contexts where conflict is endemic. The significance of this study is to divulge approaches to manage conflict to be functional amongst teachers and principals.

\subsection{Research Questions}

To reply to the problem described, the following research questions were raised to guide the study:

a) Why is it important to manage conflict between teachers and principals?

b) What are the consequences of conflict between principals and teachers?

c) Which approaches that can be applied to manage conflict to become functional between principals and teachers?

\subsection{Objectives of the Study}

In response to the above questions, the following research objectives were raised to guide the study to:

a) examine the importance of conflict management between teachers and principals;

b) describe the consequences of conflict amongst principals and teachers;

c) explore approaches that can be applied to manage conflict to become functional amongst principals and teachers

\subsection{The Conceptual Framework of the Study}

This study is guided by a concepetual framework describing the most relevant concepts related to conflict management. These concepts stem from literature and findings of prior research. By adopting this approach, our conceptual framework is in line with what Jabareen (2009:51) propose, which states that a conceptual framework is a network of interlinked concepts that provide a comprehensive understanding of a phenomenon. These interlinked concepts support one another and constitute a conceptual framework to inform the study. To this end, the conceptual framework for this study was guided by the following concepts:

(i) Conflict

Mullins (2010:197) views conflict as an inevitable factor and forms part of a social phenomenon that occurs amongst individuals or within groups, organisations, and nations on an everyday basis due to opposing behaviours such as disagreements, inconsistencies and confrontations. Moreover, it is known as something negative that negatively affects an organisation's structure and functions in the short and long term (Doğan, 2016:201).

\section{(ii) Conflict management}

Conflict management is a critical and integral part of any organisation to ensure that conflict is managed adequately in order to delimit the negative effects between individuals and on an organisation (Khan, Iqbal \& Hussainy, 2016:160).

(iii) Dysfunctional conflict management

Dysfunctional conflict management is a concept emanating from managing conflict ineffectively or being incompetent to address or manage conflict appropriately (Omisore \& Abiodun, 2014:124).

(iv) Functional conflict management

Functional conflict management refers to managing conflict positively, which results in constructive outcomes for the parties involved (Khan, Iqbal \& Hussainy, 2016:160).

\subsection{Literature Review}

Conflict is inevitable and forms part of daily life. It exists because people do not usually get along with one another or agree with one another. Conflict has long been recognised as a common occurrence in all workplaces, which can negatively affect an organisation's structure in the short and long term (Doğan, 2016: 200-201). Referring to conflict in schools in particular, Ohaka (2016:2) states that school conflict is mainly concerned with creating and establishing unfair duties, disorders, confusion and chaotic conditions among individuals, which usually stem from disagreements. What is even alarming, though — and a factor that seems to hinder progress - is some principal's inability to address complicated conflict situations (Larasati \& Raharja, 2020: 194).

The issue of conflict and all its associated challenges between principals and teachers has risen systematically over the years (Msila, 2012; Larasati \& Raharja, 2020: 194). When it comes to the roles that principals should play in addressing this challenging phenomenon, Larasati and Raharja (2020: 192) state that if principals do not handle conflict properly, it may result in dysfunctional conflict, impacting the school environment negatively. This, in turn, may prevent the school from attaining its objectives, creating mistrust, frustration and even hatred between teachers and principals. Saiti (2015) adds that dysfunctional conflict creates poorer communication channels between principals and teachers, negative work 
commitment and engagement.

Ohaka (2016:7) highlights several reasons why managing conflict in a functional manner in schools should be a priority. This author believes that conflict management strategies create a basic environmental condition for effective teaching and learning to occur. Furthermore, it helps create and maintain a stable and harmonious interrelationship of the school's human resources. Another advantage is that functional conflict management strategies can increase peaceful and harmonious cooperation between the staff. It also enhances good governance and may contribute to improving the overall productivity of the school. The principals' communication and conflict management skills positively impact teachers' work (Fajrussalam, Badrudin \& Sulhan, 2019:282).

For Salleh and Adulpakdee (2012:21), effective conflict management strategies include a sincere desire, honesty and trustfulness to do so. Both parties involved in the conflict should be open to the solution of the conflict, trying to compromise, negotiate and look at things from the other person's perspective.

\section{Methods}

\subsection{Research Paradigm and Design}

Research design - defined by Akhtar (2016:88) a the "structure or the 'glue' of the research project that keeps all the elements together"- intends, according to (Sileyew, 2019:2), to provide an appropriate framework for a research study. The design adopted in this study was a single case study design, as we focused on the experiences of staff at one school only. As the focus was on a daunting and complex challenge - conflict management - this design is deemed suitable considering what Nieuwenhuis (2020:122) opine: "that case studies provide a comprehensive overview of a complex issue".

\subsection{Research Approach}

This study employed a qualitative research approach, which Creswell (2014:4) describes as a systematic investigation into social phenomena within a natural setting. This is in line with what Rahman (2017:103) views as research on people's lives, their experiences, emotions, behaviours and feelings, as well as on social movements, organisational functioning, cultural phenomena and interactions with people. Based on these viewpoints, the qualitative approach was the most appropriate for this study, as it seeks to gain a solid understanding of these people's experiences, particularly principals and teachers' experiences regarding the management of conflict.

\subsection{Selection of Participants}

In this study, the sample consisted of ten participants, purposefully selected comprising one principal, the deputy principal and eight teachers from one rural high school in the ZF Mgcawu district in the Northern Cape province, South Africa. Cresswell and Plano Clark (2011) define this method of purposeful sampling as identifying and selecting individuals or groups of knowledgeable and well-educated individuals about the phenomenon under investigation. In line with the overall theme and aim of this study - to gather information about how conflict is managed - this sampling method and the participants selected were, therefore, the sensible choice.

\subsection{Data Collection Instruments}

In this study, data were collected through open-ended questionnaires from the selected participants. According to Albudaiwi (2017), open-ended questionnaires consist of a set of questions that do not provide participants with a predetermined set of answers to choose from. However, it allows participants to respond in their own words, which provides the research with rich, detailed data. Another motivation for selecting this method was to gather holistic and comprehensive feedback from the participants and provide them with enough time to reflect deeply about the issue at hand ( Albudaiwi, 2017).

The open-ended questionnaire consisted of six questions:

- How do you understand the term "conflict management"?

- Do you consider conflict management as a necessity or burden in the school?

- How often does conflict occur between the principal and the teachers? Why does this happen?

- How does the principal-teacher conflict affect the school culture?

- Who do you think is responsible for steering principal-teacher conflict to become functional, and why?

- What strategies or methods can be used to steer functional between principals and teachers?

\subsection{Data Analysis Procedures}

The data from the open-ended questionnaires in this study were thematically analysed and in line with the research questions. We followed the recommendation by Cohen, Manion and Morrison (2007), whereby the data were read and transcribed to look for common concepts between them. These shared concepts were then grouped into themes with the purpose of identifying common aspects and eventually provide a possible answer to the research questions. 


\subsection{Ethical Considerations}

Keeping in mind what specifically Cohen et al. (2007) and Resnik (2011) regard as important ethical considerations (the protection of participants against harm and being considerate of researching people in social sciences research), ethical protocol was rigorously attended to.

To this end, we first obtained ethical clearance from the University of the Free State (ethical clearance number: UFS-HSD2017/1063/2908), followed by permission to conduct the study from the Northern Cape Education Department. Secondly, we obtained written consent from participants indicating their willingness to partake in this study. Also, anonymity was assured in this study by not disclosing any school or participant's name. Confidentiality was assured by informing participants that the collected data would be treated confidentially and only used for research purposes.

\section{Results}

This section discusses the results of the ten open questionnaires completed by the principal, deputy principal and eight teachers. In particular, the results present the varied responses to conflict management and the functionality of conflict management amongst principals and teachers. To make sense of the varied responses, the data were encoded into the following four themes:

- Theme One: Importance of managing conflict

- Theme Two: Consequences

- Theme Three: Responsibility of managing school conflict

- Theme Four: Approaches for functional conflict

\section{Theme One: Importance of managing conflict}

From the data collected, all the participants recognised that managing conflict between principals and teachers is an absolute necessity in schools. The following comment by Participant 1 (school principal) indicates the importance of managing conflict between principals and teachers:

Managing conflict is important because if the conflict is not managed oryou do not take action, harm can be done to all parties involved.

Teachers also seem to agree with the importance of intervention. They view conflict as a necessity that can prevent violent behaviour (participant 2), which is of great benefit for the school environment (participant 3). Participant 5 adds:

It is important because it will create a tolerable working environment that is necessary for the principal and teachers to work effectively together.

The findings displayed by the participants are supported by Larasati and Raharja (2020:194), who state that managing principal-teacher conflict is crucial in the sense that it prevents disturbances from reoccurring amongst principals and teachers. This will enable them to focus on the all-important issue of the school's vision, mission and goals. Furthermore, it helps to create a stable and harmonious working culture between principals and teachers, which is for Ohaka (2016) vital as: "it helps to establish and maintain a peaceful and harmonious co-existence between the principal and teachers in the school".

\section{Theme Two: Consequences of poor conflict management}

From the participant's feedback, it is clear that conflict - if not attended to - can easily become a destructive force, jeopardizing sound, collective teamwork within the school environment, and also negatively affecting the school culture. Participant 4 for example points out: It has a negative effect. It leads to a toxic work environment, work disruptions and no teamwork.

To add, Participant 3 comments,

It affects the school culture drastically. It demotivates and demoralise the teachers. It makes it difficult for teachers to work with people with whom they in conflict with.

To support these findings, Msila (2012:33) also found in his study that consequences of principal-teacher conflict affect the school culture negatively. This author ascribes the situation to the principal's lack of capacity to deal effectively with the challenge of conflict. Omisore and Abiodun (2014:124) warn that when conflict is not effectively dealt with, it leads to a destructive environment in which relationships are broken and thus hinders the exchange of ideas amongst principals and teachers. Another reason why these consequences negatively affect the school culture may be that the principal and teachers ignore the conflict between them, which then creates space for further tension as conflict remains unresolved. This is evident from the comments of participant 6: "The principal does not have open relationships with his staff. He makes most decisions by himself. Do not inform his staff of important information from the DOE" (Department of Education).

\section{Theme Three: Responsibility of managing school conflict}

The data demonstrated that some participants felt that both parties, the principal and teacher, should be responsible for managing principal-teacher conflict to be managed functionally. Participant 5 specifically opined,

Conflict is between two people, so both (the principal and teacher) involved in the conflict are responsible for managing their conflict effectively on behalf of the school's sake and for a conducive working culture amongst staff.

This finding is in line with Salleh and Adulpakdee 
(2012:15), who also emphasise in their study that principals and teachers are jointly responsible for managing their conflict with one another and that it is not the responsibility of one person to ensure the smooth running of conflict situations.

However, others thought that principals-as the authoritative figure- are predominately responsible for managing principal-teacher conflict to be functional. Participant 2, for instance, made the following statement,

The principal is in charge of the school, so it is his/her responsibility to see that teachers can function and complete their respective jobs in harmony.

Participant 4 agreed and said,

The principal should be responsible for creating an environment where conflict can be resolved properly and peacefully for teachers and the principal to work effectively together.

Larasati and Raharja (2020:192) supported this viewpoint and highlight that the principal is the school leader and therefore responsible for creating the right school culture for all stakeholders to work effectively together. This entails the principals' responsibility to manage conflict properly to provide positive benefits that can encourage schools to be dynamic and prevent conflict from hampering any school-related activities. Interestingly enough, some participants felt that the entire school management team should be involved: "The persons responsible for the steering of the principal-teacher conflict are the School Management Team" (participant 8).

\section{Theme Four: Approaches for dealing with conflict in a functional manner}

Although participants provided varied responses, the findings did reveal some common approaches such as better communication channels, respect, identifying the cause of the conflict and putting aside differences as necessary approaches for principal-teacher conflict to become functional. Participant 4 :

open and honest yet calm and communication lines are needed for conflict to become functional amongst the principal and teachers.

Participant 2 also indicated that:

more effective communication is necessary and to listen actively to get to the root of the issue to solve the issue and more effective communication.

The school management team members commented as follows on the problem: "When something happens, resolve it the same time, and go to the roots of the problem" (HOD). The deputy principal agrees on the approach to deal swiftly but add to it the following strategies: "Leadership, active listening, mediating and modelling reasonable dialogue are important."

These common key elements relate to conflict management approaches in a functional manner and include compromising, obliging and integrating approaches. Salleh and Adulpakdee (2012:21) found that the compromising approach is an effective approach to steer conflict to be functional as it entails everyone listening and sharing each other's needs and trying to put oneself in the opponent's shoes. To support this finding, Ramani and Zhimin (2010) state that functional conflict management approaches involve listening and giving opportunities to address the needs of all stakeholders and effectively addressing their interests in order to achieve a win-win outcome for the stakeholders involved. To add, Rahim (2010:4) also states that the integrating approach is one of the most effective functional conflict management approaches, as the managing of conflict entails having great concern for oneself and being cognizant of others. This approach entails transparency, sharing of information, looking for alternatives, and analysing differences to reach an effective solution acceptable for both stakeholders. Participants' responses also related to the functional conflict management approach of obliging, which involves setting aside differences and emphasising better communication and commonalities to address the other person's concerns (Rahim, 2010:15).

\section{Conclusions}

This study revealed that conflict management plays an important role in managing and reducing principal-teacher conflict in schools. It also confirmed with literature that unattended conflict between principals and teachers has a detrimental effect on school culture and that functional conflict management strategies are necessary for conflict amongst them to be less destructive. Moreover, the study also revealed that both parties are responsible for handling conflict amongst them to be functional. However, it remains the principal's prime responsibility to ensure that he/she manages conflict at his/her school in order to establish a functional environment where he/she can work collectively with staff.

\section{Recommendations}

Based on the findings in the previous paragraphs, it is recommended that specific efforts should be put into place by principals to enhance sound cooperation between them and staff.

Workshops and professional development sessions should be conducted by principals to address this vital topic. At the Departmental level, strategies should be implemented also by departmental officials to raise awareness amongst principals and teachers on how to improve conflict management between principals and teachers. Instead of simply avoiding negative conflict situations, the aim should be to investigate conflict 
management strategies to approach conflict situations in a functional manner.

\section{REFERENCES}

[1] Akhtar, I. 2016. Research Design. In I. Akhtar (Ed.), Research in social science: Interdisciplinary perspectives.

[2] Albudaiwi, D. 2017. Surveys, advantages and disadvantages of. The Sage Encyclopedia Of Communication Research Methods, pp.1735-1736.

[3] Chadwick, B. 1995. Conflict to consensus workshop. Minneapolis, MN: Minneapolis Public School.

[4] Cohen, L., Manion, L. \& Morrison, K. 2007. Research methods in education $\left(6^{\text {th }}\right.$ ed). London: Routledge.

[5] Creswell, J.W. 2014. The selection of a research approach. In J.W. Creswell (Ed.), Research design: qualitative, quantitative, and mixed methods approaches. London: Sage.

[6] Cresswell, J.W. \& Plano Clark, V.L. 2011. Designing and conducting mixed method research ( $2^{\text {nd }}$ ed). Thousand Oaks, CA: Sage.

[7] Doğan. S. 2016. Conflicts management model in school: A mixed design study. Journal of Education and Learning, 5(2), 200-219.

[8] Fajrussalam, H., Badrudin, B. \& Sulhan, M. 2019. The influence of principal's communication and conflict management towards the work discipline of teachers at SMA PGRI Tanjungsiang Subang. In 2nd International Conference on Research of Educational Administration and Management (ICREAM 2018). Atlantis Press.

[9] Göksoy, S. \& Argon, T. 2016. Conflicts at schools and their impact on teachers. Journal of Education and Training Studies, 4(4), 197-205.

[10] Jabareen, Y. 2009. Building a conceptual framework: philosophy, definitions, and procedure. International Journal of Qualitative Methods, 8(4), 49-62.

[11] Jones, J. 2005. Management skills in schools. London: Paul Chapman.

[12] Khan, K., Iqbal, Y. \& Hussainy, S.K. 2016. Causes, effects, and remedies in conflict management. The South East Asian Journal of Management, 10(2), 152-172.

[13] Larasati, R. \& Raharja, S. 2020. Conflict management in improving schools' effectiveness. In 3rd International Conference on Learning Innovation and Quality Education (ICLIQE 2019) (pp. 191-197). Atlantis Press.

[14] Mahomed, A.K., 2014. Teachers' experiences of conflict with school principals: the impact on teachers, teaching and learning. Doctoral dissertation. Durban: University of KwaZulu-Natal.

[15] Makibi, M.A. 2010. The nature of teacher conflict and conflict management in sixteen selected primary schools in Lesotho. Masters dissertation. Durban: University of KwaZulu-Natal.

[16] Msila, V. 2012. Conflict management and school leadership. Journal of Communication, 3(1), 25-34.

[17] Mullins, L.J. 2010. Management and organisational behaviour $\left(9^{\text {th }}\right.$ ed). Essex: Pearson Education Limited.

[18] Nieuwenhuis, J. 2020. Analysing qualitative data. In K. Maree (Ed.), First steps in research. Pretoria: Van Schaik.

[19] Ohaka, N. 2016. Conflict management in schools. The role of the teacher as an in loco parentis. Munich: GRIN Verlag.

[20] Omisore, B. \& Abiodun, A. 2014. Organisational conflicts: Causes, effects and remedies. International Journal of Academic Research in Economics and Management Sciences, 3(6), 118-137.

[21] Ramani, K. \& Zhimin, L. 2010. A survey on conflict resolution mechanisms in public secondary schools: A case of Nairobi province, Kenya. Educational Research and Reviews, 5(5), 242-256.

[22] Rahman, M.S. 2017. The advantages and disadvantages of using qualitative and quantitative approaches and methods in language "testing and assessment" research: a literature review. Journal of Education and Learning, 6(1), 102-112.

[23] Resnik, D.B. 2011. What is ethics in research and why is it important? National Institute of Environmental Health Sciences, 1(10), 49-70.

[24] Rahim, M.A., 2010. Functional and dysfunctional strategies for managing conflict. In IACM 23rd Annual Conference Paper.

[25] Saiti, A. 2015. Conflicts in schools, conflict management styles and the role of the school leader: A study of Greek primary school educators. Educational Management Administration and Leadership, 43(4):582-609.

[26] Salleh, M.J. \& Adulpakdee, A. 2012. Causes of conflict and effective methods to conflict management at Islamic secondary schools in Yala, Thailand. International Interdisciplinary Journal of Education, 1(217):1-13.

[27] Sileyew, K.J. 2019. Research design and methodology. In IntechOpen, on August 7. DOI: 10.5772/intechopen.85731. Also online: https://www.intechopen.com/online-first/rese arch-design-and-methodology [Accessed in Ilorin, Nigeria: 31 August 2019].

[28] Squelch, J. \& Lemmer, E. 1994. Eight keys for effective school management in South Africa. Halfway House: South African Books publishers. 